\title{
Nurturing Environmental Stewards through Preschool Physical Design
}

\author{
Mariam Felani Shaari ${ }^{*}$, Sabarinah Sh Ahmad 1 , Izaham Shah Ismail 2 \\ ${ }^{1}$ Centre of Studies for Architecture, Faculty of Architecture, Planning \& Surveying, Universiti Teknologi MARA,, Malaysia \\ ${ }^{2}$ Centre of Postgraduate Studies, Faculty of Education, Universiti Teknologi MARA, 40200 Shah Alam, Selangor, Malaysia
}

\begin{abstract}
Environmental stewardship starts with education. This paper aims to discuss how preschools can be used to nurture environmental stewards among Malaysian children. In summary, elements of preschool physical environments can be manipulated to enhance environmental education while landscape elements such as vegetation and topography can be manipulated to maximize interaction with nature. Effective interaction with nature is the most important factor to ensure environmental awareness. Findings are useful for Malaysian designers and policy makers to ensure that preschool's physical settings support environmental education to respond to climate change and preserve the planet for future generations.
\end{abstract}

(c) 2016. The Authors. Published for AMER ABRA by e-International Publishing House, Ltd., UK. This is an open access article under the CC BYNC-ND license (http://creative commons.org/licenses/by-nc-nd/3.0/).

Peer-review under responsibility of AMER (Association of Malaysian Environment-Behaviour Researchers), ABRA (Association of Behavioural Researchers on Asians) and CE-Bs (Centre for Environment-Behaviour Studies), Faculty of Architecture, Planning \& Surveying, Universiti Teknologi MARA, Malaysia.

Keywords: Malaysian preschool ; Green preschool design ; Children environmental behaviour ; Environmental education

\section{Introduction}

As globalization moves into full swing, our notorious appetite for environmental destruction grows exponentially. This phenomenon has detrimental effects on the environment, leading to climate change and global warming. Reliance on fossil fuels, mass destruction of natural environments and poorly planned urban development are among the contributing factors prevalent in developing countries and regions such as Malaysia and the South East Asia respectively (Marhani, Adnan \& Ismail, 2013). Recent scientific findings indicate that current environmental changes significantly threatens the planet and the very existence of all inhabitants. The UNICEF Intergovernmental Panel on Climate Change (IPCC) concluded that only immediate and sustained actions will prevent climate change from causing permanent and potentially catastrophic damage to our ecosystem (UNICEF, 2012). Issues such as

\footnotetext{
* Corresponding author. Tel.: +6-012-506-0875

E-mail address: mariamfelani87@gmail.com
}

2398-4287 @ 2016. The Authors. Published for AMER ABRA by e-International Publishing House, Ltd., UK. This is an open access article under the CC BY-NC-ND license (http://creative commons.org/licenses/by-nc-nd/3.0/).

Peer-review under responsibility of AMER (Association of Malaysian Environment-Behaviour Researchers), ABRA (Association of Behavioural Researchers on Asians) and CE-Bs (Centre for Environment-Behaviour Studies), Faculty of Architecture, Planning \& Surveying, Universiti Teknologi MARA, Malaysia.

DOI: http://dx.doi.org/10.21834/e-bpj.v1i3.343 
mass destruction of valuable forests, uncontrolled release of greenhouse gasses, excessive pollution and irreversible damage to the environment must come to an end, efforts to conserve and preserve the environment must now be our primary agenda. To address this, nurturing environmental stewardship through environmental awareness and education is arguably one of the best initiatives to help promote conservative and restorative efforts among future generations towards nature - and where better to start off than with children?

In 2012, the UNICEF published a framework for environmental education to address issues of climate change and interestingly, it proposed a significant role for preschool physical environments. Exploring different methods of manipulating preschool physical environments can help improve efforts in implementing environmental education among children. This review examines the impact of access and interaction with the natural environment on environmental education among preschool children. It builds on previous distinct and remarkable studies that examine outcomes associated with children's interaction with nature and various elements of the natural preschool environment (Chawla, 2015; Olsen, 2015; Ramli, 2012; McCurdy et al., 2010; Pretty et al., 2009). This review is distinct, however, because, in addition to including more recent studies, it also includes studies done in Malaysia, addressing local issues and explore how these findings can help promote environmental awareness. It also discusses how studies and design approaches implemented from other countries can be used in Malaysia.

\section{Aim and Objectives}

The paper aims to discuss how elements of the preschool physical environment can be manipulated to enable and enhance environmental education among preschool children in Malaysia.

The objectives of this study are:

- To examine the impact of the natural environment on children education

- To assess the current efforts of Malaysian preschools to accommodate environmental education

- To discuss how elements of the preschool physical environment can be manipulated to nurture environmental stewardship by encouraging awareness and a sense of belonging to nature among children

\section{Methodology}

The methodology employed in this paper is a review of secondary data. Qualitative analyzes of findings were employed in this paper. Both quantitative and qualitative literature from various disciplines related to the title were gathered and critically analyzed. Three electronic databases were searched: Science Direct, Scopus, and Web of Knowledge, indexing Malaysian and international journals on a variety of environmental education related topics from 1970 to present. The following keywords were searched; Malaysian preschool, green preschool design, children environmental-behavior, environmental education, using titles and descriptors.

This paper started with the general understanding of the impact of natural environment on children development, followed by exploring environmental education for children, to understand the need to nurture environmental stewards at earliest possible. Preschool physical design from various locations globally was then explored, to understand how they can be tailored to support the environmental education implementation.

The limitation for this paper, mainly the challenge encountered during data collection, includes the heavy emphasis given to the physical aspect of preschool design. Literature is examined from viewpoints which are only confined to the context of the studies and topics discussed, which may render recommendations non-holistic.

To conclude, the common design strategies of environmental education-friendly preschools used in other countries was summarized, and further reviewing of all concepts were suggested. A holistic approach and expert reviewing is highly recommended to ensure that foreign design concepts are applicable in the Malaysian context. Gaps for further research identified from the analysis were also suggested. 


\section{Literature review}

\subsection{Impact of natural environment on children development}

\subsubsection{The benefits of children interaction with nature}

Children have profound affinities towards nature. They see it as their sanctuary; a site for explorative play and physical activity (Azlina \& Zulkiflee, 2012). The importance of the natural environment on the different aspects of children development have long been established among researchers (Chawla, 2015; Ahmad et al., 2015; Acar, 2014; Abbas, 2012; Cheng \& Monroe, 2012; Abbas \& Othman, 2011; Grinde \& Patil, 2009). Cognitive, social, physical, mental and physiological aspects of children development are all positively affected by consistent interaction with nature. Furthermore, physical activity and play in natural environments also help children to learn and better understand their surroundings. Through movement, children perceive their surrounding landscape via three methods of learning - cognitive, affective, and evaluative. Information gathered from these methods are interpreted and applied as a concept or idea, which are then used as the basis for acquiring knowledge in other situations or environments (Mohidin, Ismail \& Ramli, 2015). These findings suggest that natural environments positively impact children development rather than jeopardize it.

\subsubsection{Incorporating nature into the built environment}

To take advantage of the benefits natural environments have to offer, incorporating nature into the built environment is important. This idea is not new and in fact, the foundations for this conceptual understanding existed since the early 1980s. For example, Yerkes (1982) concluded that playing with landscape elements (natural and man-made) and exposure to diverse climatic factors stimulate children's senses and creativity, leading to better cognitive development. Furthermore, frequent and regular play in nature-rich environments was proven to stimulate all aspects of the child's development more readily than indoor environments, justifying a need for incorporating natural elements in the design of preschool environments (Mohidin, Ismail \& Ramli, 2015).

Indoor built environments, though safer, more structured and better planned, lack features to provide critical stimulation children need to learn and experience. Playgrounds made from manipulable materials such as cardboard boxes, toys, leaves, plants, earth, sand and water encourage children to perceive better the benefits and adversities of each element - leading to familiarity and understanding of the roles these elements play in their daily lives. Interestingly, these benefits were also seen in children with learning disabilities such as dyslexia and slow learners. It proves that natural elements are beneficial to all groups of children, regardless of age, social background and physical as well as mental condition (Ahmad et al., 2015; Soltani, Abbas \& Awang, 2012). Thus, the preschool setting for children must incorporate both natural and built environments and ensure that they work in synergy in maximizing children development (Abbas, 2012; Abbas, Othman \& Rahman, 2012; Grinde \& Patil, 2009). The benefits of both environments can be used to ensure that children are in a conducive learning environment to enable the implementation of environmental education; which will be elaborated further.

\subsubsection{Nature deprivation}

Early childhood is the most critical period of a child's development. The child's physical as well as socialemotional and cognitive development takes place speedily during this formative period (Abbas, Othman \& Rahman, 2012). It is at this crucial period that exposures to the natural environments encourage intellectual growth and cognitive learning the most and this is linked to better academic and non-academic achievements in the future. Unfortunately, nowadays, especially in developing countries such as Malaysia, it seems that societies and stakeholders have begun to neglect the importance of such environments for the development of children. What is worse is that our emphasis on mainstream preschool designs is now shifting towards encouraging children to be indoors rather than outdoors. They spend far more time being taught and evaluated on aspects of literacy and 
maths skills than they do, playing and exploring the natural world, exercising their bodies, and using their imaginations (Azlina \& Zulkiflee, 2012). This 'detachment' from the natural context is worrying, as it leads to unfavorable outcomes concerning cognitive, physical and physiological development as well as health issues such as eczema, chronic asthma, childhood obesity and Type I Diabetes (O'Brien \& Varley, 2012). A tendency to play and be entertained in front of TVs, game consoles and smartphones rather than go outside and play is becoming more apparent among children nowadays, especially in urban areas - in both developed and developing countries alike (Chawla, 2015).

Increasing deprivation and limited access to nature and its stimulative elements has led children to suffer from Nature Deficit Disorder - a condition characterized by a lack of interest and awareness of one's natural surroundings (Derr et al., 2013). Moreover, recent research also suggested that a lack of interaction with nature promotes gross ignorance towards the natural environment among children - leading to a lack of societal and political will among future generations to address key environmental and climatic issues (Chawla, 2015; Shaumann, 2013; Nussbaum, 20112). In a country renowned for its rich and diverse nature such as Malaysia, it is even more important that future generations are given the most opportunity to acquaint themselves with the environment they live.

\subsection{Environmental education for children}

\subsubsection{Nurturing young environmental stewards}

Environmental Stewardship starts with education - the earlier, the better. The key objective of environmental education among children is to promote a sense of belonging and responsibility towards the natural environment to ensure that positive attitudes are nurtured from a young age (Azlina \& Zulkiflee, 2012; UNICEF, 2012). For the past two decades, Climate Change and Environmental Education (CCEE) has become one of the major tools for combating global warming and ensuring sustainable development in the future. The Kyoto Protocol (Article 10) and the United Nations Framework Convention on Climate Change (Article 6), both encourage governments and international bodies to educate, empower and engage all stakeholders and major groups on climate change policies (UNICEF), 2012). In 2002, the United Nations General Assembly proposed and advocated the United Nations Decade of Education for Sustainable Development Initiative (2005-2014), highlighting the critical role of education in achieving sustainable development; beginning with children (UNICEF, 2012). Children must be thought to appreciate nature; they must be nurtured to have the voluntary urge to conserve and partake in efforts to preserve natural surroundings.

Though they are many approaches and theories on how environmental education can be made possible among preschool children, recent studies have found that concern for the environment is based on familiarity, love and affection. It means that environmental education is only made possible from autonomous and continuous contact with nature - the longer they spend exploring natural environments, the more they feel responsible to towards it (Chawla, 2015; Acar, 2014; Cheng \& Monroe, 2012; Nussbaum, 2011). It suggests that direct and constant interaction with nature seems to be the key here. Efforts must, therefore, be focused on achieving this to kick start environmental education initiatives.

\subsubsection{Preschool children as active participants}

The Rio Declaration on Environment and Development of 1992 confirmed the importance of children in achieving sustainable development (UNICEF, 2012). Though children are among the most vulnerable to climate change, they must not be considered passive or helpless, in fact, they should be made active participants in designing a conducive preschool environment. Through education, projects and actions, children can contribute to every aspect of climate change policymaking, mitigation, and adaptation where children can act as potent agents to bring about change (Latif, Bidin \& Awang, 2013; UNICEF, 2012). When empowered and educated on issues of climate change, 
it is observed that children can directly and will actively bring about change and contribute to sustainable development as they grow up.

The preschool age is also a crucial point in their lives to introduce environmental education. Schaumann (2013) noted that the ages between four and nine are the time when children begin to question "who am I?" and "what is my role in this world?". Allowing children to experience different possible situations in the natural environment will help to provide appropriate answers to these crucial questions - nurturing more responsible behavior among children towards their surrounding environment (O'Brien \& Valey, 2012; Abbas \& Ghazali, 2010). It is at this stage when educators should introduce children to nature as much as possible to promote empathy, affinity and a sense of belonging towards it. Thus, again, stakeholders must, therefore, tailor the design of physical environments to maximize effective interaction with nature, enabling environmental education.

\subsection{Preschool physical design: enabling environmental education}

\subsubsection{Theoretical foundation}

Various studies support the use of physical elements in preschools to promote responsibility towards the natural environment among children (Kelz, Evans \& Röderer, 2015; Hinds \& Sparks, 2007; O'Brien \& Murphy, 2007). The Theory of Planned Behavior is the theoretical basis for the use of physical design in promoting environmental awareness (Hinds \& Sparks, 2007). It suggests that both active connection and identification with the surrounding natural environment would contribute significantly to the prediction of people's intentions to appreciate and to preserve it.

As explained earlier in 4.2, promoting effective interaction with natural elements acts as the stepping stone to ensure that desired behaviors can successfully be nurtured among preschool children - this is where the design of preschool physical environments come into play. In assisting the implementation of Theory of Planned Behavior, the physical environment of preschool should be environmental education-friendly designed. It must be designed to accommodate and encourage children to interact with nature more frequently to achieve the objectives of environmental education programs. Without frequent direct interactions with nature, it is impossible to nurture and maximize environmental awareness and instill positive values in future generations. Figure 1 summarizes the conceptual approach commonly adopted in developed countries to design environmental education-friendly preschools.

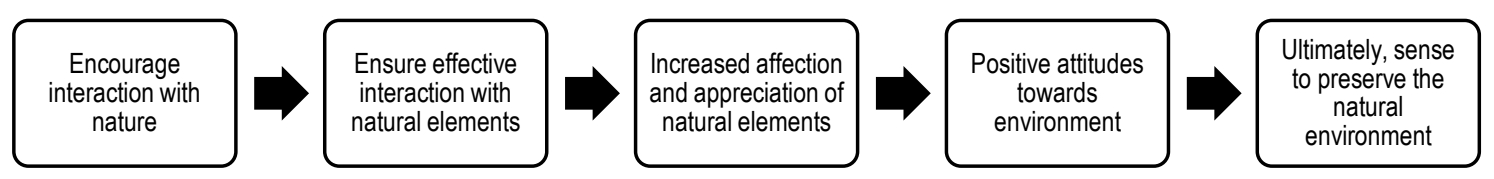

Fig. 1. A theoretical approach to environmental education-friendly preschools. (Chawla, 2015; Kelz, Evans \& Röderer, 2015; Olsen, 2015; Azlina \& Zulkiflee, 2012; Thompson, Aspinall \& Montarzino, 2007).

\subsubsection{Preschool physical design approaches}

In an effort to support environmental education, many strategies have been proposed to bring children closer to nature. To begin with, designing preschool physical environments for environmental education must first ensure that it provides a welcoming atmosphere for children - adequate natural lighting, proper ventilation, and use of warm and appropriate colors to stimulate comfort among children (Kelz, Evans \& Röderer, 2015). Both learning and play spaces should be clean, friendly, and inviting, and must come with appropriate storage to be used by staff and children (Acar, 2014; Spencer \& Wright, 2014). These strategies are important because by doing so, preschools will 
be equipped to accommodate better CCEE programs - allowing seamless and effective education among preschool children to ensure that environmental education objectives are achieved (Ramli et al., 2012).

Outdoor play spaces, on the other hand, must be designed as an extension of the classroom - creating physical and social environments where children feel similarly welcomed and safe. There must also be a balanced blend of natural and man-made elements - Children show the highest degree of interest in playgrounds that have a combination of both elements (Spencer \& Wright, 2014). All elements should also be age appropriate for them to use to ensure that it is safe and appropriate for their level of development. It is important to go down to this level as children will only be able to perceive environmental values if they are familiar and comfortable with them. This familiarity will enable children to interact effectively with natural elements and achieve the objectives proposed in Figure 1.

Another design concept to encourage children learning and environmental awareness is 'greening' preschools or redesigning preschools with more natural elements (Ramli et al., 2012). The key here is to incorporate as much natural stimulus into the preschool environment as possible. There are many elements and components of a 'green' preschool building that can be manipulated to promote an environment rich in natural stimuli such as building orientation, indoor environment quality, vegetation, and topography. Examples of effective methods to implement this include allocating areas for gardening activities to encourage children to learn and appreciate efforts of environmental conservation as well as placing pictures of various common species of flora and fauna to enable familiarity among children. Using toys and furniture that resemble natural elements regarding feature and color will help make children feel more comfortable being in nature-like settings. Moreover, placing locally-unique plants or shrubs in classroom and activity areas will help to enable exposure to nature even during formal education. Allocating more spaces with manipulable natural objects - trees, rocks, sand, earth, and water is also proven to be one of the effective implementation methods (Ramli et al., 2012). All these initiatives expose children to a diversified natural environment, enabling input from different types and aspects of nature. It is important because not all natural elements are known to preschool children due to their tender age. Therefore, exposure to natural diversity will help them to learn. It will also allow children to evaluate every element in closer proximity, giving them ample time and opportunity to understand and feel a part of nature itself (Azlina \& Zulkiflee, 2012).

\section{Findings and discussion}

It is interesting and significant that UNICEF has identified preschool as an essential element for environmental education; why then have the Malaysian authorities been moving away from the environmental experience in their preschool designs? Efforts to foster 'greener' preschools are still minimal - especially in urban areas and among government preschools. There is yet to be a government-led, well-coordinated national guideline and policy on CCEE. Though awareness of the importance of this subject matter is encouraging, the social initiative and political will are still at a comparatively early stage - developed countries are leaps and bounds ahead of Malaysia (Mohidin, Ismail \& Ramli, 2015; Latif, Bidin, \& Awang, 2013). This situation prompts further study into the attitudes of stakeholders among Malaysian preschools and the factors that surround it.

Many environmental education-friendly schools across the world have incorporated CCEE into their design (UNICEF, 2012). In other countries, several design strategies have been found to be commonly adopted in preschools designed to accommodate environmental education (Kelz, Evans \& Röderer, 2015; UNICEF, 2012; Hinds \& Sparks, 2007). These strategies were proposed to nurture environmental stewardship by encouraging familiarity with natural elements and ensure that children are consistently in proximity with diverse natural elements throughout their time in preschools. These strategies are also coherent with the theoretical approach highlighted in Figure 1, whereby the first step towards environmental education is to encourage interaction with nature.

Currently in Malaysia, lessons on issues such as global warming, the greenhouse effect, and natural disasters are not enough to elicit awareness among young generations (Latif, Bidin \& Awang, 2013). Thus, strategies to raise awareness must be implemented to enhance the effects of environmental education programs for children and their society. A good way to achieve this is by placing various facilities within the preschool compound to promote 
environmental-friendly behavior. In Albania, for example, the Child-Led Environmental Education Program encouraged recycling habits by placing recycling bins in classrooms, playgrounds, and canteens (UNICEF, 2012). As a result, nearly half of the children in selected schools adopted, at least, one environmentally-friendly behavior at home.

Guaranteeing a safe and child-friendly physical environment is also another important approach. Governmentendorsed CCEE projects in Malaysia are likely to start in Ministry of Education (MOE) preschool buildings. As highlighted earlier, physical activities, especially in natural environments will expose children to hazards; therefore, all furniture and facilities must be child-friendly - devoid of sharp edges, of appropriate height and material and must also be safe. School environments can also be child-friendly by visually incorporating environmental education messages in paintings and murals. Children were directly involved in the 2004 post-tsunami reconstruction and repair of schools in Sri Lanka with some of their murals included messages on how to protect the environment to prevent global disasters in the future (UNICEF, 2012). This initiative showcased the key fundamental principles of child-friendly schools: child-centeredness and participation. The efforts can also be implemented in Malaysian preschools to encourage conservative environmental attitudes among preschool children.

Designing 'green' schools is also another key strategy by promoting better exposure to natural elements among preschool children (Latif, Bidin \& Awang, 2013). Well-designed green preschools must not only incorporate plants and nature into most common areas, but they must also provide comfort, ample natural lighting, be energy efficient, ensure good indoor air quality and ventilation (Kelz, Evans \& Röderer, 2015). This way, preschools can be both 'greener' and sustainable - achieving two key objectives of sustainable building design. The Green Preschool Project in Bali, Indonesia encourages preschools to be built almost exclusively with bamboo - a cheap locally renewable resource. The preschools were found to be more sustainable as a result. But more importantly, from an environmental education point of view, this effort helped achieve a bigger objective - to develop responsible and green habits among its students. Designing sustainable buildings in Malaysia is still a challenge, and this approach to designing preschools may help address this issue.

On the other hand, bringing children closer to nature does not necessarily mean encouraging more outdoor activity. In trickier situations, where space is scarce such as in crowded urban areas, designers can instead devise preschool physical environments that work in ensuring that children are constantly exposed to natural elements even though they are indoors - indirectly making children involved with nature. This approach has its perks too; on top of maximizing children interaction with natural elements, it also helps to manage the unwanted risks associated with outdoor activity among children. The risks include air and noise pollution (especially in urban areas), animal bites (especially in tropical countries), communicable diseases and accidents during outdoor play (GhanbariAzarneir et al., 2015).

Considering all design concepts gathered, the best approach is to implement a mixed setting whereby various aspects of the outdoor and indoor physical environment are manipulated to enhance environmental education. Figure 2 below summarizes the recommended design aspects that should be considered in designing Malaysian preschools suitable for environmental education.

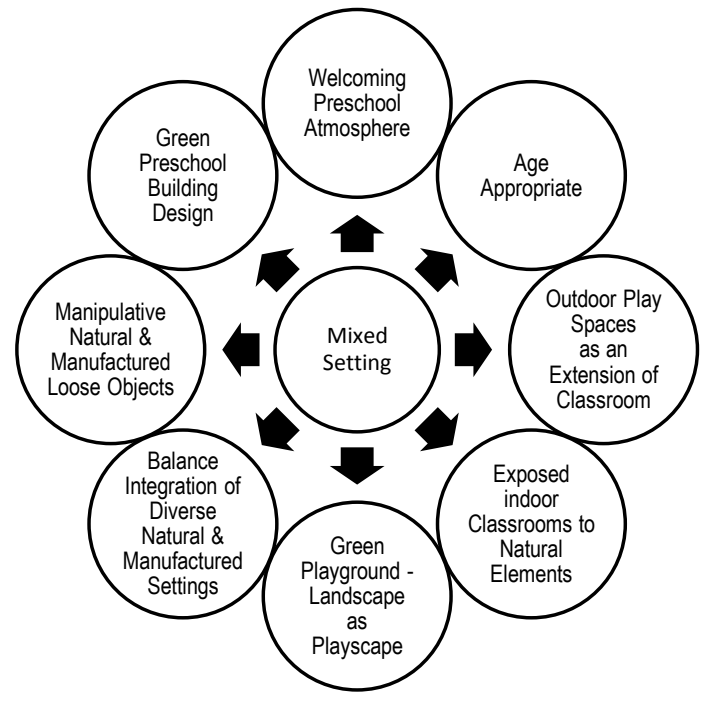


Fig. 2. Mixed Settings - The recommended design approaches to enable and enhance environmental education among Malaysian preschools. (Ghanbari-Azarneir et al., 2015; Spencer \& Wright, 2014; Acar, 2014; Kelz, Evans \& Röderer, 2013; Azlina \& Zulkiflee, 2012).

\section{Conclusion}

In summary, most design concepts implemented in other countries have the potential to be implemented in Malaysia but must go through expert reviewing by a multi-disciplinary panel which includes practitioners from various backgrounds. Due to certain social, administrative and geographical issues, not all of the approaches used are applicable in Malaysia. Design concepts have to be adapted and induced by Malaysian educators to ensure that many aspects of children education are properly considered. Designing preschool environments for environmental education, however, revolve around allowing safe but continuous and uninterrupted contact between children and natural elements. This concept should be the foundation of all preschool design in Malaysia to ensure that future generations are better equipped to combat and respond to global climate change. It is hoped that findings from this paper can then be reviewed and analyzed to ensure effective implementation in Malaysia. Environmental stewardship is the key to a greener Malaysia, and it starts with children.

\section{Recommendation}

Some successful design concepts can be tailored to suit Malaysian settings. However, they require multidisciplinary, expert reviewing and to ensure that they are applicable in the Malaysian setting. Experts may include those from fields of children education, pediatric medicine and psychology, architecture and urban planning and government personnel. Issues, for example, shading, and preschool orientation must be seriously considered because of Malaysia's hot humid climate - European preschools can afford to have open playgrounds with minimal shading, whilst Malaysian preschools cannot. Maximizing indoor natural lighting can also be tricky - unlike countries in seasonal climates, Malaysian preschools cannot just allow maximal unobstructed natural light, especially during midday, due to high UV levels and undesirable temperatures. But fortunately, this should not hinder Malaysians from exploring other possible avenues to implement the key design strategies implemented in other countries. With more study and better grasps of the fundamental principles of environmental education, efforts will be easier to transform Malaysian preschools into institutions of environmental education.

\section{Acknowledgements}

The authors would like to thank the Ministry of Higher Education, Malaysia, for the funding given under the Fundamental Research Grant Scheme (FRGS). The authors would also like to thank IRMI, Universiti Teknologi MARA for administering the grant.

\section{References}

Abbas, M. Y., \& Othman, M. (2011). Social Behaviours between Urban and Non-Urban Pre-School Children. Procedia-Social and Behavioral Sciences,30, 2001-2009. 
Abbas, M. Y., Othman, M., \& Rahman, P. M. A. (2010). Pre-school children's play behaviour influenced by classroom's spatial definitions. Asian Journal of Environment-Behaviour Studies (ajE-Bs), 1(1), 49-66.

Abbas, M. Y., Othman, M., \& Rahman, P. Z. M. A. (2012). Pre-school Classroom Environment: Significant upon Childrens' Play Behaviour?.Procedia-Social and Behavioral Sciences, 49, 47-65.

Acar, H. (2014). Learning Environments for Children in Outdoor Spaces.Procedia-Social and Behavioral Sciences, 141, 846-853.

Ahmad, S. S., Shaari, M. F., Hashim, R., \& Kariminia, S. (2015). Conducive Attributes of Physical Learning Environment at Preschool Level for Slow Learners. Procedia-Social and Behavioral Sciences, 201, 110-120.

Azlina, W., \& Zulkiflee, A. S. (2012). A pilot study: The impact of outdoor play spaces on kindergarten children. Procedia-Social and Behavioral Sciences,38, 275-283.

Chawla, L. (2015). Benefits of Nature Contact for Children. Journal of Planning Literature, 30(4), 433-453, 0885412215595441.

Cheng, J. C. H., \& Monroe, M. C. (2012). Connection to Nature Children's Affective Attitude toward Nature. Environment and Behavior, 44(1), 31 49.

Derr, V., Chawla, L., Mintzer, M., Cushing, D. F., \& Van Vliet, W. (2013). A city for all citizens: Integrating children and youth from marginalized populations into city planning. Buildings, 3(3), 482-505.

Ghanbari-Azarneir, S., Anbari, S., Hosseini, S. B., \& Yazdanfar, S. A. (2015). Identification of Child-friendly Environments in Poor Neighborhoods.Procedia-Social and Behavioral Sciences, 201, 19-29.

Grinde, B., \& Patil, G. G. (2009). Biophilia: does visual contact with nature impact on health and well-being?. International journal of environmental research and public health, 6(9), 2332-2343.

Hinds, J., \& Sparks, P. (2008). Engaging with the natural environment: The role of affective connection and identity. Journal of Environmental Psychology, 28(2), 109-120.

Horayangkura, V. (2012). Incorporating environment-behavior knowledge into the design process: An Elusive Challenge for Architects in the 21 st Century.Procedia-Social and Behavioral Sciences, 50, 30-41.

Intergovernmental Panel on Climate Change (2007) 'Climate Change: The physical science basis', Fourth Assessment Report, IPCC, Geneva, accessed on the 10 February 2016 from

https://www.ipcc.ch/publications_and_data/publications_ipcc_fourth_assessment_report_wg1_report_the_physical_science_basis.htm

Kelz, C., Evans, G. W., \& Röderer, K. (2013). The restorative effects of redesigning the schoolyard: A multi-methodological, quasi-experimental study in rural Austrian middle schools. Environment and Behavior, 0013916513510528.

Latif, S. A., Bidin, Y. H., \& Awang, Z. (2013). Towards the Realization of Green Cities: The moderating role of the residents' education level. Procedia-Social and Behavioral Sciences, 85, 646-652.

McCurdy, L. E., Winterbottom, K. E., Mehta, S. S., \& Roberts, J. R. (2010). Using nature and outdoor activity to improve children's health. Current problems in pediatric and adolescent health care, 40(5), 102-117.

Mohidin, H. H. B., Ismail, A. S., \& Ramli, H. B. (2015). Effectiveness of Kindergarten Design in Malaysia. Procedia-Social and Behavioral Sciences,202, 47-57

Nussbaum, M. C. (2011). Creating Capabilities. Cambridge, MA: Harvard University Press.

O'Brien, L., \& Varley, P. (2012). Use of ethnographic approaches to the study of health experiences in relation to natural landscapes. Perspectives in public health, 132(6), 305-312.

Olsen, H. M. (2015). Planning Playgrounds: A Framework to create Safe and Inclusive Playgrounds, Journal of Facility Planning, Design and Management, 3 (1), 57-71.

Pretty, J., Angus, C., Bain, M., Barton, J., Gladwell, V., Hine, R., ... \& Sellens, M. (2009). Nature, childhood, health and life pathways. Occasional Paper, 2.

Ramli, N. H., Masri, M. H., Zafrullah, M., Taib, H. M., \& Hamid, N. A. (2012). A comparative study of green school guidelines. Procedia-Social and Behavioral Sciences, 50, 462-471. 
Schauman, S. (2013). The Genius of Childhood: The Life and Ideas of Edith Cobb. Children Youth and Environments, 23(2), 194-207.

Soltani, S. H. K., Abbas, M. Y., \& Awang, M. B. (2012). Disabled children in public playgrounds: A pilot study. Procedia-Social and Behavioral Sciences,36, 670-676.

Spencer, K. H., \& Wright, P. M. (2014). Quality Outdoor Play Spaces for Young Children. YC Young Children, 69(5), $28-34$.

Thompson, C. W., Aspinall, P., \& Montarzino, A. (2007). The childhood factor: Adult visits to green places and the significance of childhood experience.Environment and Behavior.

UNICEF (2012). Climate Change and Environmental Education, accessed on the 12 February 2016 on the http://www.unicef.org/publications/files/CFS_Climate_E_web.pdf

Yerkes, R. (1982). A Playground that Extends the Classroom. ERIC. Document 239802. Vol.6, No.4 (Winter), Miami University. 